Review

\title{
Nanomaterials for Electrochemical Energy Storage: the Good and the Bad
}

\author{
Maria Rosa Palacín, ${ }^{1,2} *$ Patrice Simon ${ }^{1,3}$ and Jean Marie Tarascon ${ }^{1,4}$ \\ ${ }^{1}$ ALISTORE-ERI European Research Institute \\ ${ }^{2}$ Institut de Ciència de Materials de Barcelona (ICMAB-CSIC) Campus UAB, E-08193 Bellaterra, Catalonia, (Spain) \\ ${ }^{3}$ Université Paul Sabatier, CIRIMAT, UMR CNRS 5085, 118 route de Narbonne 31062 Toulouse Cedex (France) \\ ${ }^{4}$ FRE 3677 “Chimie du Solide et Energie”, Collège de France, 11 Place Marcelin Berthelot, 75231 Paris Cedex 05 (France) \\ * Corresponding author: E-mail: rosa.palacin@icmab.es
}

Received: 02-02-2016

In memory of prof. dr. Janko Jamnik.

\begin{abstract}
Abstract: A critical view on the outcome of research in nanomaterials for electrochemical energy storage devices (batteries and supercapacitors) is provided through selected examples. The nano- approach traces back to the early battery research and its benefits realized even before the nano- term was coined. It has enabled important progresses which have translated, for instance, in the possibility of using $\mathrm{LiFePO}_{4}$ as electrode material. On the other hand, the nano- approach has also been oversold at all levels and hence some examples are also shown on the detrimental side effects of the use of nano-materials which should be taken into account if steady progress is to be made that finally results in practical benefits in energy storage devices.
\end{abstract}

Keywords : Nanomaterials, electrochemical energy storage, batteries, supercapacitors

\section{Introduction}

Richard Feynman is considered the father of the nano-revolution, and his 1959 visionary statement « There's plenty of room at the bottom » will remain forever. It took a few years for the "nanomania" to take off and to emerge near the end of the 90's, prior to boost in the early years of the current century. Since then, nanomaterials entered all application domains ranging from medicine to construction with staggering benefits in the field of microelectronics sector.

In 2011 the EU gave a definition for nanomaterials as "A natural, incidental or manufactured material containing particles, in an unbound state or as an aggregate or as an agglomerate and where, for $50 \%$ or more of the particles in the number size distribution, one or more external dimensions is in the size range $1 \mathrm{~nm}-100 \mathrm{~nm} .{ }^{1}$ This adage does not greatly differ from the one given by the International Organization for Standardization (ISO): »Material with any external dimension in the nanoscale or ha- ving internal structure in the nanoscale « with Nanoscale meaning »Size range from approximately $1 \mathrm{~nm}$ to 100 $n m . \ll$

With such a background, one could naively think that the application of nanomaterials in the energy storage field is unravelling novel cross cutting science which is going to revolutionize the figures of merit for battery and supercapacitor performance in the second millennium. Nonetheless this is not strictly true... The "nano-" prefix has indeed been coined relatively recently and now applied in all fields but nanomaterials are much older than that and some beneficial aspects realized longtime ago. Indeed, dealing with electrochemical energy storage and nickel based batteries (first patents by Jüngner in Sweden and Edison in the US around 1900) it soon was established that high surface area $\mathrm{Ni}(\mathrm{OH})_{2}$ exhibits higher capacity than well-crystallized $\mathrm{Ni}(\mathrm{OH})_{2}$. Indeed, it is stated $\mathrm{in}^{2}$ that: The nickel (II) hydroxide used in flat positive electrodes must have a very large active surface area. Investigations have shown that there is a definite relationship 
between the surface area of the nickel material and the capacity. Therefore, when the material is being prepared, the goal must be to obtain the smallest possible particles. It has been shown that a satisfactory nickel (II) hydroxide for flat pocket cells ordinarily consists of crystals in the form of small disks with a height of only 20-60 $\AA$ and a width of 100-400 A. Similarly the field of fuel cells had greatly benefited from nanosized electrode materials.

Early research on nanomaterials science can be traced back to the chemistry of colloids, which does nowadays sound much less fancy! Electrochemical energy storage being ultimately based on an electronic transfer at the atomic scale, one can rigorously state that all electrochemical processes are by definition nano- and thus, foresee a high impact of nanoscience in battery and supercapacitor research. "Real" commercial batteries typically consist of composite electrodes casted on a metal current collector and aside the active materials do also contain additives to enhance the electronic conductivity (typically some sort of carbon black) and a polymer to improve adhesion and mechanical strength. Thus, many types of interfaces between all components exist at the nanometric scale, which may exhibit different properties thus influencing ionic transport and the ultimate device performance. ${ }^{3}$ Altough researchers rapidly catched up with the buzzword nano to successfully apply for funding, we must admit that the practical ingress of nanomaterials in today's commercial Li-ion cells has been limited: only $\mathrm{LiFePO}_{4}$ and $\mathrm{Si}$ electrodes have benefited from it. Supercapacitors have also enjoyed the new nano era with the copious use of nanotextures and nanoarchitectured electrodes. High surface area carbons are commonly used as active materials, and the design of the nanosized electrode / electrolyte interface is one the key challenges to improve the electrochemical performance of supercapacitors ${ }^{4}$ (Figure 1).
Overall, in addition to temperature, pressure, and composition, size has provided an extra dimension to both battery and supercapacitor communities for tuning electrochemical device performances. Size does indeed matter: on one side progressive nanosizing brings about decreased ionic diffusion paths and better strain accommodation, on the other, there are also negative sides of the story as the enhanced surface area results in lower packing density while enabling also catalysis, hence promoting undesired side reactions. Within this overall context, the aim of this paper is to give a realistic overview of the benefits of nanomaterials in the field of electrochemical energy storage while at the same time pointing out some the drawbacks through some selected examples as small does not systematically rhyme with better...

\section{Pros: the Importance of Being Small}

The size reduction of particles to the nano level leads to a huge increase in the fraction of atoms that reside at its surface while at the same time decreasing the travelling distance for ions from the core to the surface. This has tremendous implications for Li-ion systems in which the charge/discharge rate is controlled by the lithium ions diffusion rate in the electrodes and thus across all existing interfaces and inside the active material particles. Moreover, although frequently omitted, size reduction involves significant changes in surface energy which can have important consequences such as the feasibility to stabilize anatase over rutile. ${ }^{5}$ Similarly, the redox potential values can be substantially affected by nanoeffects. $^{6,7}$

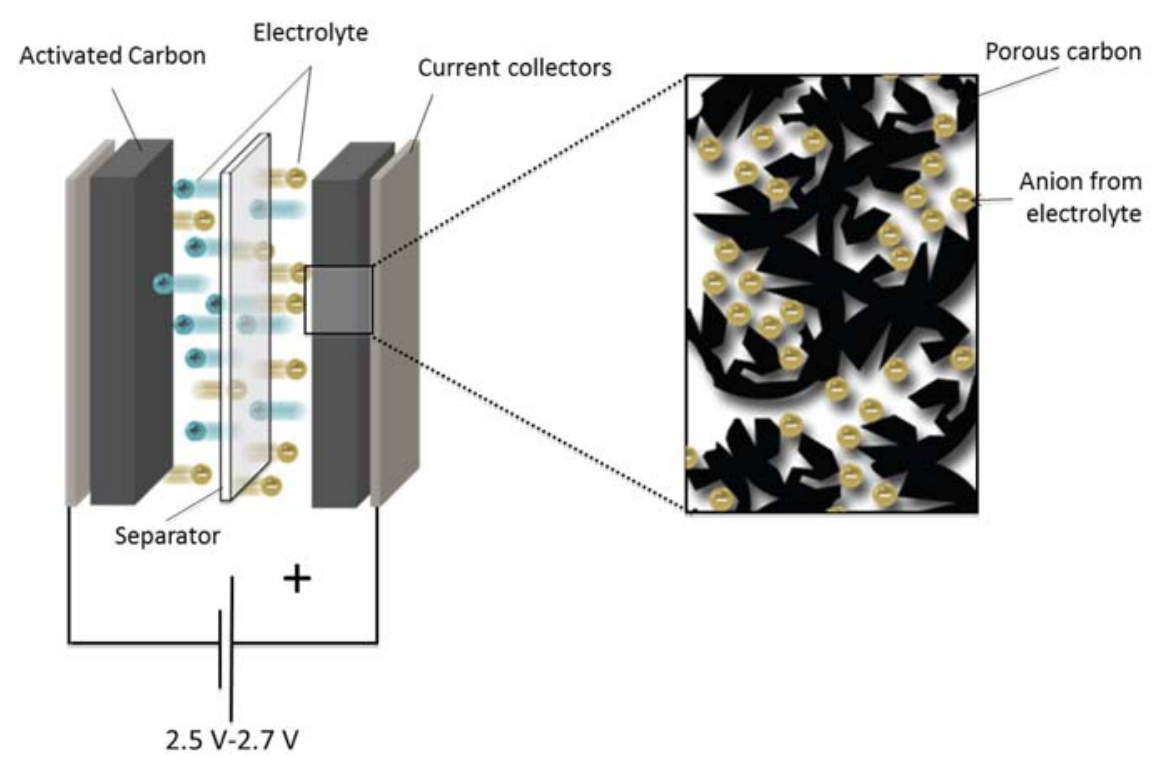

Figure 1: Schematics of a supercapacitor (left) and porous carbon at the positive electrode containing adsorbed anions. 
Besides the already mentioned traditional example dealing with nickel based batteries, the investigation of nanomaterials in lithium battery research has flourished in the last decade covering not only Li-ion electrode materials but also alternative technologies such as Li/Air or $\mathrm{Li} / \mathrm{S}$. A pedagogical example to convey the benefits of Nanomaterials is $\mathrm{LiFePO}_{4}$, a mineral that was totally ignored for centuries, and which is now used in commercial batteries for power tools and also electric vehicles. In this case, the material can only be rendered useful if particles are covered by a thin (few nm thickness) conductive carbon coating to enable effective electronic transport. ${ }^{8}$ Once this is achieved, by further playing with the particle size it is feasible to orient the Li-uptake/removal towards an homogeneous single-phase or an heterogeneous two-phase process. ${ }^{9}$ This can be rationalized in terms of the energy associated with the strains induced by volume changes between the lithiated and de-lithiated phases. ${ }^{10}$ Of course, the magnitude of such effects is affected by the cycling rate which determines the kinetics of the reaction. ${ }^{11}$ Moreover, caution has to be exercised because nanomaterials are in most of the cases heavily rich in defects, so that distinguishing between the effect of defects of nano sizing is complex. Nonetheless nanostructuration cannot be taken as the panacea since it failed to deliver comparable results in $\mathrm{LiFePO}_{4}$ isostructural phases with alternative transition metal such as $\mathrm{Mn}$, Ni or Co instead of Fe, which exhibit higher redox potential and hence could lead to batteries with enhanced energy densities. In fact, in this case, owing to higher redox potentials $\left(>4 \mathrm{~V} \mathrm{vs}\right.$. $\mathrm{Li}^{+} / \mathrm{Li}$ for $\mathrm{LiMPO}_{4}$ when compared to $3.5 \mathrm{~V}$ for $\mathrm{LiFePO}_{4}$ ), having high surface areas promotes catalytic-driven electrolyte decomposition.

The benefits of downsizing can also be inferred from recent progresses in the $\mathrm{Li} / \mathrm{S}$ technology which is not commercialized yet but for which prototypes are foreseen in the next coming years. In this case, rather than acting on the active materials, researchers have played on nanoconfinment strategies enlisting amongst others core-shell like approaches or designing yolk-shell like structures. Here the active cathode material is Sulphur, which is unexpensive and highly abundant and reduces upon discharge to form a range of polysulphides (with different degrees of solubility in the electrolyte) to ultimately yield solid $\mathrm{Li}_{2} \mathrm{~S}$. Aside the problem of soluble species migrating and contaminating the counter-electrode, the insulating nature of sulfur and $\mathrm{Li}_{2} \mathrm{~S}$ is an issue for high charge/discharge rates. The introduction of nanostructured mesoporous carbon-sulphur composites as cathodes was a breakthrough in the field ${ }^{12}$ since the intimate contact between the insulating sulphur and the conductive carbon framework enabled higher and more reversible capacities while at the same time delaying the diffusion of soluble polysulphides and thus diminishing capacity fading. This has prompted the screening of different types of carbon and the fabrication of a vast spectrum of composite electrodes as the functionalization of carbon was found to be an interesting approach to prevent polysulfide diffusion. More recent approaches may exhibit enhanced complexity such as the use of composites containing graphene to anchor sulfur and confine polysulfides coupled to nano fibrillated cellulose to prevent graphene exfoliation. ${ }^{13}$ Alt-
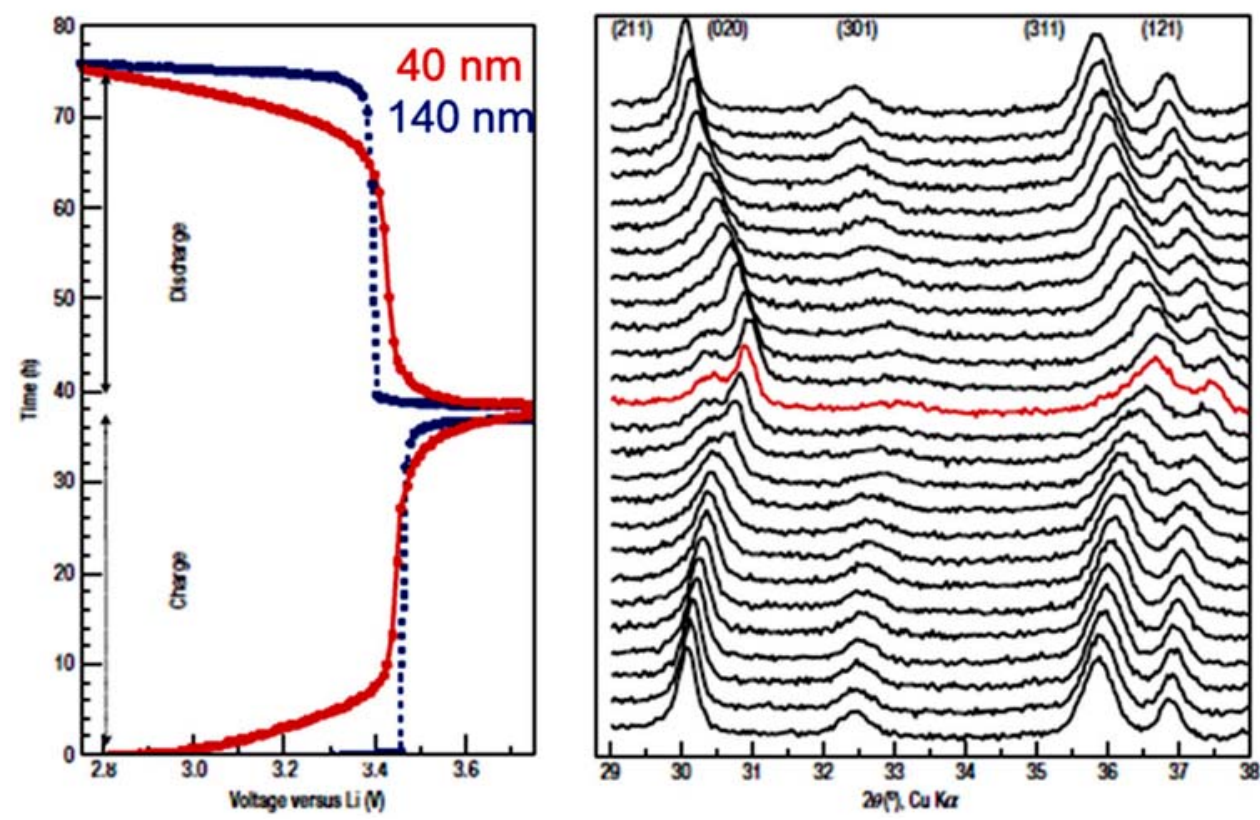

Figure 2. Electrochemical profiles corresponding to $\mathrm{LiFePO}_{4}$ with different particle size $40 \mathrm{~nm}$ (in red) and $140 \mathrm{~nm}$ (in blue) at C/40. In situ XRD measurements indicate continuous shift of the diffraction peaks during the $40 \mathrm{~nm} \mathrm{LiFePO}$, characteristic of a solid solution redox mechanism. The red pattern corresponds to the fully delithiated phase. (Reprinted from ${ }^{11}$ with permission) 
hough elegant, such approaches have the handicap that non-polar entities such as carbon cannot bind to sulfur. Being aware of such an issue, researchers decided to move to more polar supports such as oxides while keeping the confinement approach, hence the use of zeolites or metal organic framework structures (MOF). ${ }^{14}$ When instead of insulating phases electronically conducting oxides are used, boosted performance improvements are achieved. ${ }^{15}$ Using $\mathrm{Ti}_{4} \mathrm{O}_{7}$ nanoparticles which strongly bind to thiol-based species sustained capacity retentions $((>2500)$ could be achieved for electrodes having $\mathrm{S}$ loadings greater than $75 \%$. The issue is now to find the way to practically implement such stylish nanomaterials through developing upscaling synthesis procedures and electrode formulation protocols having high sulfur loadings while decreasing the amount of electrolyte to enable figures of merit beyond the Li-ion technology in terms of practical energy density. ${ }^{16}$ Needless to said that for safety reasons, the Li would most likely have to be replaced by an insertion electrode, that would most likely penalize energy density or else develop a strategy to avoid its dendritic growth, which will still take a few years of sustained research.

Nanomaterials can also trigger novel reactivity mechanisms such as conversion reactions as demonstrated in 2000. ${ }^{17}$ Until that time all electrode materials used in
Li-ion batteries worked according to a classical insertion/deinsertion process or by electrochemically forming Li alloys. Defying these well-established laws, reversible redox activity was measured for transition metal oxides (MO) that did not have the required structure to enable insertion reactions, and containing metals $(\mathrm{M})$ cannot alloy with $\mathrm{Li}$. The high capacity values achieved $(>700 \mathrm{mAh} / \mathrm{g}$ for nearly 100 cycles) were explained by the existence of

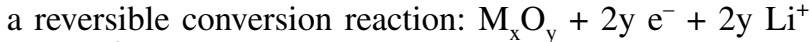
$\rightleftarrows \mathrm{x} \mathrm{M}^{0}+\mathrm{y} \mathrm{Li} 2 \mathrm{O}$ forming a composite consisting of a ho-
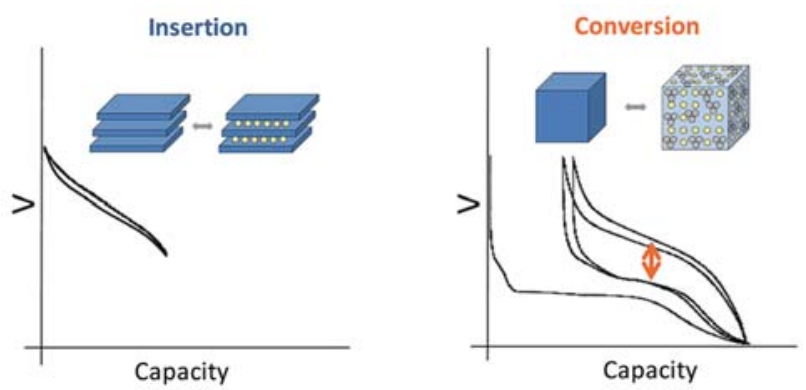

Figure 3. Schematic representation and typical potential vs. capacity profile for conventional insertion and alternative conversion reaction pathways in lithium-ion battery electrodes. (Reprinted from ${ }^{18}$ with permission)

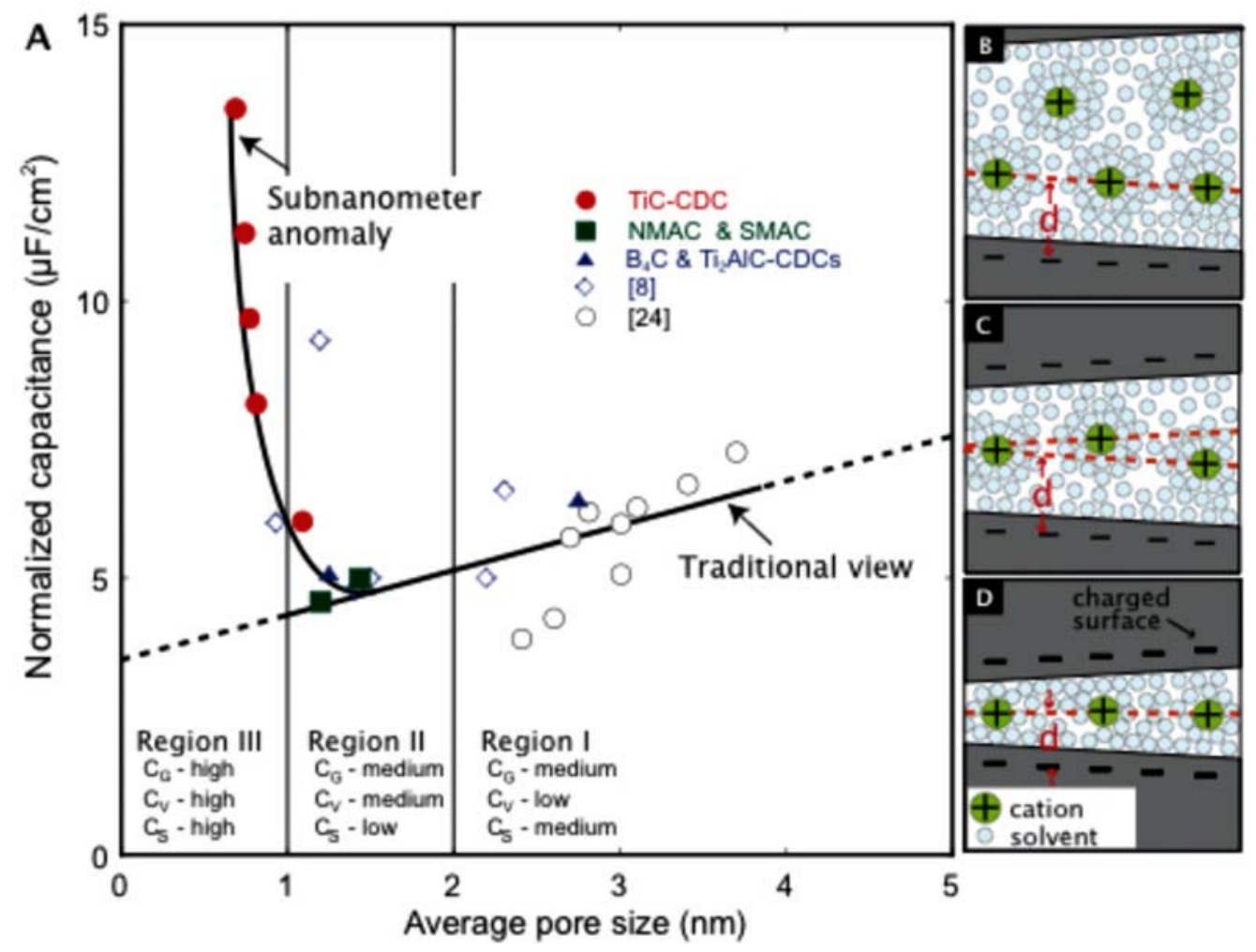

Figure 4: Plot of specific capacitance normalized by BET specific surface area for the carbons in the study and two other studies with identical electrolytes (A). The normalized capacitance decreases with pore size until a critical value is reached. It would be expected that as the pore size becomes large enough to accommodate diffuse charge layers, the capacitance would approach a constant value. CG, CV and CS are gravimetric, volumetric and normalized capacitances, respectively. Illustrations showing solvated ions residing in pores with distance between adjacent pore walls (B) greater than $2 \mathrm{~nm},(\mathrm{C})$, between $1 \mathrm{~nm}$ and $2 \mathrm{~nm}$ and (D) less than $1 \mathrm{~nm}$ illustrate this behavior schematically. (Reprinted from ${ }^{20}$ with permission) 
mogeneous distribution of metal nano particles in a matrix of $\mathrm{Li}_{2} \mathrm{O}$.

All together, it was rapidly demonstrated that this surprising reactivity, contrary to well-established beliefs, was not specific to oxides, but can also include sulfides, nitrides, fluorides and hydrides. In contrast to the classical insertion reactions that govern the energy stored in the actual $\mathrm{Li}$-ion batteries, and which are limited to $1 \mathrm{e}^{-}$even $0.5 \mathrm{e}^{-}$per $3 \mathrm{~d}$ metal atom $\left(\mathrm{LiCoO}_{2}\right)$, these new conversion reactions can involve $2 \mathrm{e}^{-}$or even more (per $3 \mathrm{~d}$ metal atom), thus enabling extremely high capacities. Such results have enjoyed a tremendous worldwide resonance but unfortunately batteries based on conversion reaction are not likely to be ever commercialized owing to issues dealing with intrinsic large potential hysteresis resulting in poor energy efficiency. ${ }^{19}$

An interesting example of the benefit of nanosize can be found in supercapacitors. Unlike traditional batteries, supercapacitors store the charge electrostatically through reversible adsorption of ions from an electrolyte at the surface of high surface area porous carbons (up to $2,000 \mathrm{~m}^{2} / \mathrm{g}$ ) thanks to the presence of sub-nanometer size pores $(<1 \mathrm{~nm})$. Under polarization, the adsorption of ions in these small, confined carbon nanopores leads to a huge increase in the charge storage capacitance of the carbon (Figure 4). ${ }^{20}$ Another key result was obtained by studying the ion adsorption in Carbide Derived Carbons (CDC) in solvent-free electrolyte, using neat $\mathrm{EMI}^{+} \mathrm{TFSI}^{-}$solution, where it was we found that the maximum capacitance is obtained when the carbon pore size matches the ions si$z e .^{21}$ These results ruled out at that time the way charge storage was traditionally described in Electric DoubleLayer Capacitor (EDLC) materials, with ions adsorbed on both pore walls. Although the whole mechanism is not still completely understood, recent works have shown that the capacitance increase in carbon nanopores of $1 \mathrm{~nm}$ or
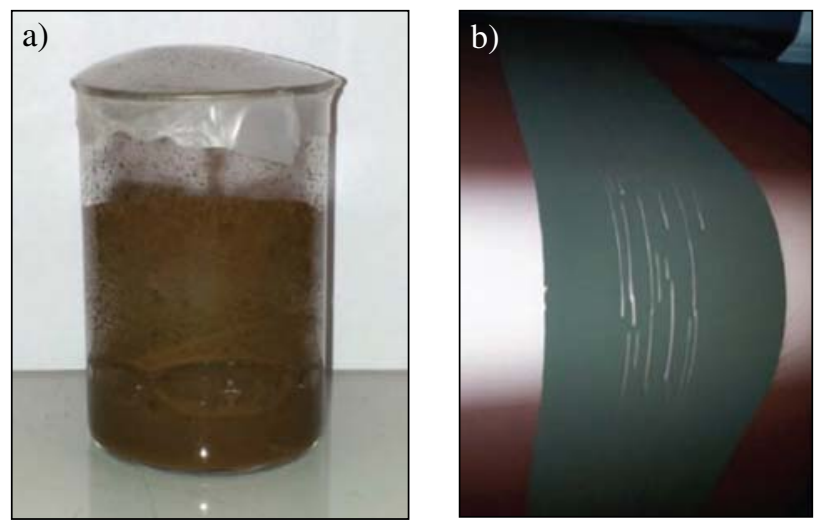

Figure 5. (a) Picture showing the gas $\left(\mathrm{H}_{2}\right)$ production during the mixing of a suspension containing Si nanoparticles to prepare an electrode. (b) Resulting Cu-supported casted electrode where bubbles in the slurry have induced a non-uniform coating. Reprinted from ${ }^{26}$ with permission. below was ascribed to the partial desolvation of the ions when confined in these small pores, as well as a decrease of the approaching distance of the ions to the carbon surface. $^{22-24}$ Despite confinement, ion migration is still fast between various adsorption sites. ${ }^{25}$ The capacitance increase in carbon pores thus highlights the beneficial attributes of nanosizing the carbon structure. Therefore, as for batteries, the supercapacitor community fell into the development of fancy nanoarchitectured objects via multiple synthetic steps, with the global electrode fabrication process being far from practical reality, which is the next challenge the community is facing.

\section{Cons: the Other Side of the Coin}

Elements forming electrochemical alloys with lithium (such as Si for instance) hold promise to enable high energy density as their electrochemical capacities (e.g. $3589 \mathrm{mAh} / \mathrm{g}$ for formation of $\mathrm{Li}_{15} \mathrm{Si}_{4}$ ) are well beyond that of graphite $(372 \mathrm{mAh} / \mathrm{g})$ which is currently the negative electrode material of choice in almost all commercial Liion batteries. Such a high capacity is thus the result of a huge increase in the number of atoms present in each active particle, which creates strains and cracks inducing enhanced reactivity with the electrolyte and thus alloy based materials suffer from severe capacity fading. Materials engineering strategies have been applied to solve the issue, and significant improvements have been recorded through nanostructuration (particles less prone to break upon stress) or the use of nanocomposites with a conducting matrix (e.g. carbon) buffering the volume expansions. In spite of lower tap densities and enhanced reactivity with the electrolyte due to the enhanced surface area coupled to the low operation potential, significant improvements have been made at the laboratory scale although commercialization is restricted to the use of 3-4\% silicon as additive in graphite electrodes. Indeed, even after developing methods to produce nanosized $\mathrm{Si}$ at the large scale their implementation in commercial electrodes can be penalized due to technological hurdles. Indeed, typical fabrication protocols involve dispersion of the active materials and additives in a solvent (either organic or water) to form slurries that are subsequently tape casted on current collectors. Given the interest in defining greener process and the beneficial effect of using some water soluble species as binders, processing in water seems to be more adapted. Yet, nanosized Si oxidizes under such conditions producing hydrogen which results both in inability to fabricate good quality electrodes and safety risks. Fortunately, alternative strategies based in controlled oxidation of such particles (up to $10 \mathrm{~nm}$ ) to avoid such effects seem to be successful. Yet, this may also limit the electrochemical capacity and thus, careful design of processing protocols are needed if these processes are ever to be implemented to result in tangible improvements in energy density for Li-ion batteries. 
Thus, it is important to state that "nano" does not always mean "better" when it comes to electrodes and scientists should realize that making materials for the sake of it does not bring significant performance improvements but rather serves only to publish irrelevant papers. One key parameter which has to be considered prior to blindly move to nanosizing is the redox potential at which the electrode material is operating. Any attempt to apply the dual nanosizing/nanocoating approach which has been successfully used for $\mathrm{LiFePO}_{4}$ or even $\mathrm{LiFeBO}_{3}(2.9 \mathrm{~V}$ $\mathrm{Vs} . \mathrm{Li}^{+} / \mathrm{Li}$ ) fails for other electrode materials operating at potential greater than $4 \mathrm{~V}$, whatever they are $\mathrm{LiMPO}_{4}$, $\mathrm{Li}-\mathrm{NMC}$, Li-rich NMC or $\mathrm{LiMn}_{2} \mathrm{O}_{4}$ and its derivative $\mathrm{LiMn}_{2-\mathrm{x}} \mathrm{Ni}_{\mathrm{x}} \mathrm{O}_{4}$. The reason behind, is, as state above, that such materials operate beyond the thermodynamic stability of the electrolyte and thus its catalytic decomposition is promoted by nanosized electrode materials. Coating techniques are presently used to passivate surfaces and enable use of these highly oxidizing materials. A possible alternative option to circumvent these issues consists in developing electrolytes which are more stable against oxidation, a challenge that we have been targeting for decades without real success. In absence of such electrolytes, trying to prepare nanosized $\mathrm{Li}-\mathrm{NMC}$ or $\mathrm{Li}$-rich $\mathrm{NMC}$ in order to bring higher rate capability to the expense of an energy density penalty associated to lower density powders is a dead end route.

\section{Conclusion}

Through this short discussion illustrated with a few selected examples we have attempted to convey the message that nanomaterials, which can be viewed as "chips off the block" of old materials, can occasionally stand as serious candidates to power the next generation of $\mathrm{Li}$-ion batteries or alternative technologies. This has been demonstrated in the development of $\mathrm{LiFePO}_{4}$ positive electrodes powering today electric vehicles and $\mathrm{Si}$-based negative electrodes which are on the verge to be implemented. Equally, nanoarchitectured electrodes have led to staggering progresses in the development of $\mathrm{Li} / \mathrm{S}$ technology while supercapacitors have also greatly benefited from electrode nanotexturing. Application-wise, we can just incite researchers to report performances in $\mathrm{Wh} / \mathrm{l}$ rather than in $\mathrm{Wh} / \mathrm{kg}$, the former being more meaningful in practice even if not conveying the full benefits of nanomaterials. Energy conversion devices, enlisting photovoltaics or water splitting have greatly benefited as well from the nano approach and will keep benefiting in the future. However, efficient research towards the implementation of nanomaterials must be cross-disciplinary so as to as identify problems and provide viable options. Too frequently, researchers do make nanomaterials for the sake or the beauty of it, as conveyed by beautiful microscopy images which are flooding the literature. Indeed, research on na- nomaterials has greatly developed because of the great progresses made by microscopists over the last few decades. Has this been good or bad for namomaterials? The bets are open. In any case, the fact that nanomaterials have obliged experimentalists to push existing analytical technics to their limits and to develop new ones capable of deciphering interfaces has resulted in precious tools for the battery community.

\section{Acknowledgement to Prof. J. Jamnik}

Besides experimentation, nanomaterials were also viewed as troublemakers to theoreticians within the battery field. Indeed DFT calculations could not be blindly implemented owing to the importance of surface energy or the outcome of the band structure when entering the nanoworld, which is still subject to intense debates, not to mention issues related to true potential. Prof. J. Jamnik had aggressively and energetically attacked these difficult issues at the early stage of ALISTORE by constituting a working group on Theory to address these issues. Owing to his friendly enthusiasm and visionary contributions, he brought the field to a satisfactory level of understanding and this via long lasting and lively passionate discussions that we fully enjoyed and for which we admired his real patience. His last goal was to understand mixed potentials in theoretical terms, Janez, you left too early with the solution that you could not share with us. Fortunately you left countless great memories to all of us that are tied to our lives and will remain forever.

\section{References}

1. http://ec.europa.eu/environment/chemicals/nanotech/faq/definition_en.htm (accessed January 2016)

2. S. U. Falk, A.J. Salkind. Alkaline Storage Batteries. John Wiley\&Sons Inc. New York 1969 p. 56.

3. J. Jamnik, M. Gaberscek. MRS Bulletin 2009, 34, 942. http://dx.doi.org/10.1557/mrs2009.217

4. P. Simon, Y. Gogotsi. Nat. Mater. 2008, 7, 845. http://dx.doi.org/10.1038/nmat2297

5. A. Navrotsky. Geochem. Trans. 2003, 4, 34. http://dx.doi.org/10.1186/1467-4866-4-34

6. M. N. Obrovac, J. R. Dahn. Phys. Rev. B 2000, 61, 6713. http://dx.doi.org/10.1103/PhysRevB.61.6713

7. O. Delmer, P. Balaya, L. Kienle, J. Maier. Adv. Mater. 2008, 20, 501. http://dx.doi.org/10.1002/adma.200701349

8. M. Armand, M. Gauthier, J. F. Magnan, N. Ravet, World Patent 2001, WO 02/27823, A1.

9. P. Gibot, M. Casas-Cabanas, L. Laffont, S. Levasseur, P. Carlach, S. Hamelet, J.M. Tarascon, C. Masquelier. Nat. Mater. 2008, 7, 741. http://dx.doi.org/10.1038/nmat2245

10. A. Yamada, H. Koizumi, S. I. Nishimura, N. Sonoyama, R. 
Kanno, M. Yoneimura, T. Nakamura, Y. Kobayashi. Nat. Mater. 2006, 5, 357. http://dx.doi.org/10.1038/nmat1634

11. H. Liu, F. C. Strobridge, O. J. Borkiewics, K. M. Wiaderek, K. W. Chapman, P. J. Chupas, C. P. Grey. Science 2014, 344, 1252817. http://dx.doi.org/10.1126/science.1252817

12. X. Ji, K. T. Lee, L. F. Nazar, Nat. Mater. 2009, 8, 500. http://dx.doi.org/10.1038/nmat2460

13. M. U. M. Patel, N. D. Luong, J. Seppala, E. Tchernychova, R. Dominko. J. Power Sources 2014, 254, 55. http://dx.doi.org/10.1016/j.jpowsour.2013.12.081

14. R. Demir-Cakan, M. Morcrette, F. Nouar, C. Davoisne, T. Devic, D. Gonbeau, R. Dominko, C. Serre, G. Ferey, J. M. Tarascon. J. Am. Chem. Soc. 2011, 133, 16154. http://dx.doi.org/10.1021/ja2062659

15. Q. Pang, D. Kundu, M. Cuisinier, L. F. Nazar. Nat. Commun. 2014, 5, 4759. http://dx.doi.org/10.1038/ncomms5759

16. M. Hagen, S. Dörfler, P. Fanz, T. Berger, R. Speck, J. Tübke, H. Althues, M.J. Hoffmann, C. Scherr, S. Kaskel. J. Power Sources 2013, 224, 260. http://dx.doi.org/10.1016/j.jpowsour.2012.10.004

17. P. Poizot, S.Laruelle, S. Grugeon, L. Dupont, J. M. Tarascon. Nature 2000, 407, 496. http://dx.doi.org/10.1038/35035045

18. A. Ponrouch, J. Cabana, R. Dugas, J. L. Slack, M. R. Palacin. RSC Adv. 2014, 4, 35988. http://dx.doi.org/10.1039/C4RA05189K
19. J. Cabana, L. Monconduit, D. Larcher, M. R. Palacin. $A d v$. Mater. 2010, 22, E170. http://dx.doi.org/10.1002/adma.201000717

20. J. Chmiola, G. Yushin, Y. Gogotsi, C. Portet, P. Simon, P. L. Taberna. Science 2006, 313, 1760. http://dx.doi.org/10.1126/science.1132195

21. C. Largeot, C. Portet, J. Chmiola, P. L. Taberna, Y. Gogotsi, P. Simon. J. Am. Chem. Soc. 2008, 130, 2730. http://dx.doi.org/10.1021/ja7106178

22. C. Merlet, B. Rotenberg, P. A. Madden, P. L. Taberna, P. Simon, Y. Gogotsi M. Salanne. Nat. Mater. 2012, 11, 306. http://dx.doi.org/10.1038/nmat3260

23. J. M. Griffin, A. C. Forse, W. Y. Tsai, P. L. Taberna, P. Simon, C. P. Grey. Nat. Mater. 2015, 14, 812. http://dx.doi.org/10.1038/nmat4318

24. C. Merlet, C. Pean, B. Rotenberg, P. A. Madden, B. Daffos, P. L. Taberna, P. Simon, M. Salanne. Nat. Commun. 2013, 4, 2701. http://dx.doi.org/10.1038/ncomms3701

25. C. Pean, B. Daffos, B. Rotenberg, P. Levitz, M. Haefele, P. L. Taberna, P. Simon, M. Salanne. J. Am. Chem. Soc. 2015, 137, 12627. http://dx.doi.org/10.1021/jacs.5b07416

26. A. Touidjine, M. Morcrette, M. Courty, C. Davoisne, M. Lejeune, N. Mariage, W. Porcher, D. Larcher. J. Electrochem. Soc. 2015, 162, A1466.

http://dx.doi.org/10.1149/2.0301508jes

\section{Povzetek}

$\mathrm{S}$ pomočjo izbranih primerov, je v članku podan kritičen pogled na raziskave nanomaterialov v napravah za shranjevanje energije (baterije in superkondenzatorji). Nanotehnološki pristop in njegove prednosti so bili v baterijskem svetu poznane že pred monžično uporabo termina nano. Uporaba nanotehnologije je omogočila pomemben razvoj na področju uporabe $\mathrm{LiFePO}_{4}$ kot elektrodnega materiala. Pomembno pa je tudi omeniti, da se je nemalokrat nanopristop prepotenciral na vseh nivojih. Od tu izhajajo nekateri opisani primeri, ki kažejo diametralne stranske efekte pri uporabi nanomaterialov. Le-te je potrebno prav tako upoštevati, če želimo narediti korak naprej pri praktičnem razvoju naprav za shranjevanje energije. 